\title{
Efeitos das variações sazonais do clima tropical úmido sobre as águas e sedimentos de manguezais do estuário do rio Marapanim, costa nordeste do Estado do Pará
}

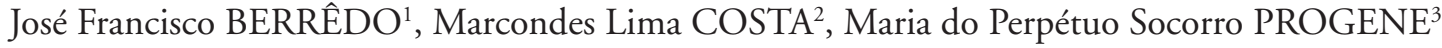

\begin{abstract}
RESUMO
Para avaliar o impacto das variaçôes climáticas, de curta duração, sobre os ecossistemas de manguezais amazônicos, foi estudada a

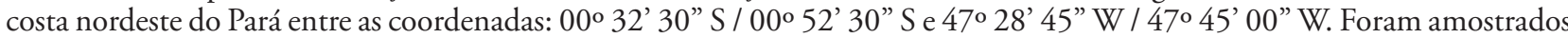
os sedimentos, águas superficiais e intersticiais com medidas de salinidade, potencial hidrogeniônico $(\mathrm{pH})$, potencial de oxiredução $(\mathrm{Eh})$ e determinaçōes mineralógicas por difração de raios X e microscopia eletrônica de varredura. Na água foram determinados o conteúdo de sulfetos dissolvidos, sulfato e cloreto, além da alcalinidade, sílica, ortofosfato, sódio, potássio, cálcio e magnésio, em meses chuvosos e de estiagem, sob marés de sizígia e quadratura.

As variaçôes sazonais do cloreto nas águas intersticiais mostram concentrações mais elevadas na estiagem que no período chuvoso, enquanto em superfície são mais elevadas nas marés de quadratura (período chuvoso) e de sizígia (período de estiagem). Os sulfetos dissolvidos foram encontrados em quantidades detectáveis somente a partir da profundidade de $10 \mathrm{~cm}$ o que indica exposição dos sedimentos aos fluxos advectivos de oxigênio atmosférico. Os teores de ferro dissolvido aumentam entre 0-10 $\mathrm{cm}$ e o potencial hidrogeniônico $(\mathrm{pH})$ tende à neutralidade. A saturação das águas intersticiais na estiagem é indicada pelos minerais evaporíticos: gipso e halita.

As variaçōes pluviométricas são responsáveis por graduais mudanças nos teores de nutrientes e nas propriedades físico-químicas $(\mathrm{pH}$, Eh e salinidade) das águas superficiais e intersticiais, no controle do equilíbrio salino das águas costeiras, na salinização e dessalinização dos sedimentos e na distribuição da vegetação de mangue no estuário. A exposição prolongada dos sedimentos na estiagem e as características morfológicas contribuem decisivamente para a oxidação total ou parcial dos sedimentos em superfície, o que modifica a mineralogia e as características químicas e físico-químicas das águas intersticiais.
\end{abstract}

PALAVRAS-CHAVE: mineralogia, geoquímica, água intersticial, manguezais

\section{Effects of seasonal variations' on the mangroves' waters and sediments of the Marapanim estuary, northeast coast of Para State \\ ABSTRACT}

To evaluate the short period climatic variations impact over Amazonic mangrove ecosystem, studies were carried out on the northeast coast of Para State. Sediments, surficial and interstitial waters were collected and examinated throughout salinity, $\mathrm{pH}$ and $\mathrm{Eh}(\mathrm{mV})$ measurements; mineralogical determination using X-ray diffraction and electronic microscopy. Chemical analysis of dissolved sulfides, sulfate and chloride, among others were made in samples collected seasonally, under spring and neap tides conditions.

The seasonal chloride variations in the interstitial waters shows $20 \mathrm{~g} / \mathrm{l}$ during the dry season and less of $10 \mathrm{~g} / \mathrm{l}$ in the season; the concentration in surficial are higher at neap tides (rainy season) and spring tide (dry season). The dissolved sulfides were found only at $10 \mathrm{~cm}$, indicating sediment exposure to the atmospheric oxygen advectives fluxes. The dissolved iron rates increases between $0-10 \mathrm{~cm}$ and the $\mathrm{pH}$ tends to neutrality. The saturation of interstitial waters at dry season is indicated by evaporitic minerals: gypsum and halite.

The pluviometric variations are responsible by gradual changes in the nutrient and physical chemical properties of surficial and interstitial waters, into the saline equilibrium control at coastal waters, in the salinization and desalinization of sediments and the distribution of mangrove vegetation at the estuary. The prolonged exposure of sediments during the dry season and the morphological characteristics contribute to the total or partial oxidation of surficial sediments, modifying the mineralogy of sediments and the physical chemical characteristics of interstitial waters.

KEY-WORD: mineralogy, geochemistry, intersticial water, mangroves

${ }^{1}$ Museu Paraense Emílio Goeldi. berredo@museu-goeldi. Av Perimetral 1901, CEP 66077-530. Tel. 91 3217-6156 fone/fax 913274-6159

${ }^{2}$ Universidade Federal do Pará. mlc@ufpa.br. Av. Augusto Corrêa, s/n CEP 66075-110. 91 3249-5028

${ }^{2}$ Universidade Federal do Pará. helpprogene@bol.com.br. Av. Augusto Corrêa, s/n CEP 66075-110. Tel. 91 3249-5028 


\section{INTRODUÇÃO}

Os ecossistemas costeiros amazônicos estão submetidos à conjunção de 3 tipos de forçantes: a atmosférica, a oceânica e a amazônica (Pavê, 2003). De grande importância para o setor nordeste da costa paraense, a forçante atmosférica depende das migrações N/S da ZCIT (Zona de Convergência Intertropical), responsável pelo regime dos alísios e das precipitações, e que determina a alternância das estações climáticas e a hidrologia dos rios locais.

As forçantes caracterizam-se por periodicidades próprias e, também, por variabilidades que se exprimem segundo escalas de tempo e de espaço diferenciadas e múltiplas, cujos impactos são determinantes no funcionamento e na estruturação dos espaços litorâneos, como na costa da Guiana Francesa (Pavê, 2003).

Em clima equatorial quente e úmido (Caiena, Guiana Francesa), sob regime de meso-marés (2,5 m) e chuvas de 3000 $\mathrm{mm} / \mathrm{ano}$, os efeitos climáticos sobre os sedimentos costeiros são notáveis. Alterações significativas foram registradas nas propriedades físico-químicas ( $\mathrm{pH}$, Eh e salinidade intersticial), na mineralogia e propriedades físicas dos sedimentos, quando a região é submetida a intensos processos de evapotranspiração (Baltzer et al., 1995; Baltzer et al., 2004; Marchand et al., 2004; Fiot e Gratiot, 2006).

Sob o clima tropical chuvoso da costa do Pará, estudos realizados por Schwendenmann (1998), Lara e Dittmar (1999), Dittmar e Lara (2001) e Schwendenmann et al. (2006), registraram a variação sazonal do fluxo de nutrientes e sua influência sobre os processos biogeoquímicos e nas propriedades físicas dos sedimentos do manguezal da zona Bragantina, distante aproximadamente $110 \mathrm{~km}$ do estuário do rio Marapanim.

O principal objetivo da presente pesquisa é comprovar os efeitos do clima em manguezais do estuário do rio Marapanim e demonstrar, que nesse setor costeiro, dominado por macro marés, com altos índices pluviométricos e estiagem característica, os efeitos da sazonalidade climática são marcantes sobre as águas superficiais, intersticiais e sedimentos, com prováveis reflexos sobre a vegetação.

\section{MATERIAL E MÉTODOS}

Os pontos de amostragem foram plotados em uma base cartográfica georeferenciada, em escala de 1:100.000 (Faure, 1999), (figura 1). A análise da rede de drenagem foi realizada a partir da interpretação de imagens Landsat (2001), pertencente ao Museu Paraense Emílio Goeldi, e fotografias aéreas (1:70.000) da Companhia de Pesquisa e Recursos Minerais. A interpretação da rede de drenagem, juntamente com os aspectos morfológicos e as informaçōes realidade- terreno sobre os tipos e a distribuição da vegetação de mangue, subsidiaram a seleção das áreas de amostragem.

Foram escolhidos dois setores para amostragem de sedimentos: o setor A, localizado ao norte da cidade de Marapanim e o setor B, localizado rio acima, ao sul. Nesses setores foram definidos 5 transectos (perfis I, II, III, IV e V) nivelados topograficamente com nível automático; neste artigo utilizou-se apenas os dados dos perfis I, II e IV.

Ao longo dos transectos foram coletados 60 testemunhos de sedimentos, distantes $100 \mathrm{~m}$ entre si em intervalos de 0-5 $\mathrm{cm}, 5-10 \mathrm{~cm}, 10-20 \mathrm{~cm}$; na seqüência adotou-se o intervalo de $20-20 \mathrm{~cm}$ até a profundidade máxima de $2 \mathrm{~m}$. Utilizouse um testemunhador metálico, semi-cilíndrico, de $3 \mathrm{~cm}$ de diâmetro, especial para coletar lama não perturbada. As coletas aconteceram no final do período chuvoso (junho) e no final da estiagem (novembro).

A salinidade intersticial foi medida com um refratômetro manual (ATAGO), mediante a extração, sob pressão, de algumas gotas de água intersticial. Medidas de $\mathrm{pH}$ e $\mathrm{Eh}(\mathrm{mV})$, foram obtidas com um equipamento da marca Metrhom 744 , até 2 horas após a coleta, mediante a inserção do eletrodo de vidro de $\mathrm{pH}$ e do eletrodo de platina (Eh) diretamente no sedimento (Garrels e Christ, 1965; Baltzer, 1982; Marius, 1985). O eletrodo para leituras de $\mathrm{pH}$ foi calibrado periodicamente com soluções-padrão de $\mathrm{pH} 4$ e 7 (escala NIST) e os sulfetos, que ocasionalmente aderem ao eletrodo de platina, retirados com uma lixa extremamente fina para não danificar o metal (Garrels e Christ, op cit.).

Análises mineralógicas, por difração de raios-X, foram realizadas em amostras secas a $18{ }^{\circ} \mathrm{C}$ durante 5 dias. Para a identificação da amostra total foi utilizado o método do pó e para a caracterização dos argilominerais, lâminas orientadas pelo método "pipette-on-glass" (Thorez, 1976). As amostras foram analisadas no difratômetro de raios-x Philips, modelo PW 3710, com anodo de cobre $(\mathrm{Cuk \alpha 1}=1,54060 \AA$ Á), ajustado a $45 \mathrm{kV}$ e $40 \mathrm{~mA}$. Os minerais foram identificados com o auxílio do software APD (PHILIPS) e Minerva, com banco de dados do ICDD - International Center for Diffraction Data.

A micromorfologia dos minerais e a morfologia de restos biológicos, principalmente carapaças de diatomáceas, foram investigadas com auxílio de microscópio eletrônico de varredura (MEV) LEO 1450 VP, com sistema de energia dispersiva (EDS 500 DP). As amostras foram dispersas com uma gota de água deionizada e fixadas a uma plataforma metálica por uma fita de carbono EMITEC K550 (3 x 10-1 bar e $25 \mathrm{~mA}$ ).

Para a distribuição granulométrica as amostras foram secas em estufa a $50{ }^{\circ} \mathrm{C}$, durante 2 dias; pulverizadas em grau de ágata e separadas as fraçóes silte-argila da areia por 
peneiramento a úmido (peneira de $0,063 \mathrm{~mm}$ ); o silte foi separado da argila por centrifugação a $1000 \mathrm{rpm}$ durante 5 minutos.

A amostragem de água intersticial foi realizada no setor A, apenas nos testemunhos de sedimentos com características redutoras tendo em vista a quase ausência de água nos sedimentos oxidados das zonas dessecadas. As coletas aconteceram em maio, junho, novembro e dezembro, em marés de sizígia e quadratura, nas profundidades de $0 \mathrm{~cm}$, 0-10 cm, 30-40 cm e 55-65 cm.

A água intersticial foi obtida por centrifugação do sedimento (15g/5000 rpm/5 minutos) em uma centrífuga da marca Karl Kolb; a amostra foi preservada e armazenada em atmosfera inerte de nitrogênio. Amostras adicionais de água superficial também foram coletadas.

Nas águas intersticiais foram determinados os teores de sulfetos totais dissolvidos (Cline, 1969); ferro total dissolvido (ortofenantrolina) após filtração em membrana Millipore (Millex-GP) de 0,22 $\mu \mathrm{m}$; sulfato (turbidimetria com sulfato de bário) e cloreto (volumetria com nitrato de prata). Nas amostras de águas superficiais e intersticiais foram medidas a salinidade, o pH e o potencial de oxiredução (somente nas águas intersticiais). A alcalinidade total foi analisada segundo o método de Gran (Grasshoff, 1983), a sílica e o ortofosfato (Carmouze, 1994), o $\mathrm{Na}^{+}, \mathrm{K}^{+}, \mathrm{Ca}^{2+} \mathrm{e} \mathrm{Mg}^{2+}$, por espectrometria de absorção atômica.

As águas superficiais foram coletadas em marés de enchente e vazante ao longo do rio Marapanim, quase simultaneamente às coletas de água intersticial. As amostragens foram realizadas nos meses de maior precipitação pluvial (março e julho) e em períodos de estiagem (setembro e novembro). A água foi coletada próximo à superfície $(1 \mathrm{~m})$ e no fundo do rio (máximo de $10 \mathrm{~m}$ ), utilizando-se uma garrafa de Nansen. Nas águas superficiais foram analisados os mesmos parâmetros químicos e físico-químicos das águas intersticiais.

\section{CARACTERÍSTICAS DA ÁREA DE ESTUDO}

O estuário do rio Marapanim está localizado na costa nordeste do estado do Pará, a leste da desembocadura do rio Amazonas, nas coordenadas: 00 32' 30" S / 00 52' 30" S e $47^{\circ} 28^{\prime} 45^{\prime \prime} \mathrm{W} / 47^{\circ} 45^{\prime} 00^{\prime \prime} \mathrm{W}$ (figura 1). Situa-se no centro de grandes sistemas de circulação atmosférica e oceânica tropical que, juntamente com a descarga hídrica e sedimentar do rio Amazonas, exerce influência direta na dinâmica costeira atual (Prost, 1997).

A região é dominada pelo clima tropical úmido, influenciada pela ZICT, que determina precipitaçóes pluviométricas de 2500-3000 mm entre os meses de janeiro a abril e um período de estiagem característico entre os meses de julho a dezembro, caracterizado por baixas precipitaçôes (inferiores a $60 \mathrm{~mm}$ ) e temperaturas relativamente altas, em torno de $27,7^{\circ} \mathrm{C}$ (média anual), (SUDAM, 1984). A umidade relativa do ar situa-se entre $80-85 \%$ (média anual), associada ao regime de chuvas (Martorano et al., 1993).

Nesse segmento costeiro, as águas são extremamente misturadas, influenciado por macro-marés semi-diurnas (amplitude $>5 \mathrm{~m}$ ). Do ponto de vista geomorfológico é uma costa de rias, formada por vales fluviais parcialmente submersos durante o Holoceno. A Formação Barreiras (Paleógeno) é a principal formação geológica da área e fonte de areias, siltes e argilo-minerais (principalmente caulinita e ilita), quartzo e oxi-hidróxidos de ferro para os manguezais.

Os sedimentos dos manguezais (Holoceno) apresentam como característica geral, teores de silte (de $70 \%$ ), argila (de 10 a $20 \%$ ) e areia, menos que $10 \%$. A mineralogia é constituída por quartzo, caulinita, ilita e minerais autigênicos: esmectita, sulfetos (principalmente pirita), gipso e halita, identificando-se também restos de folhas, raízes e carapaças de animais e abundantes diatomáceas.

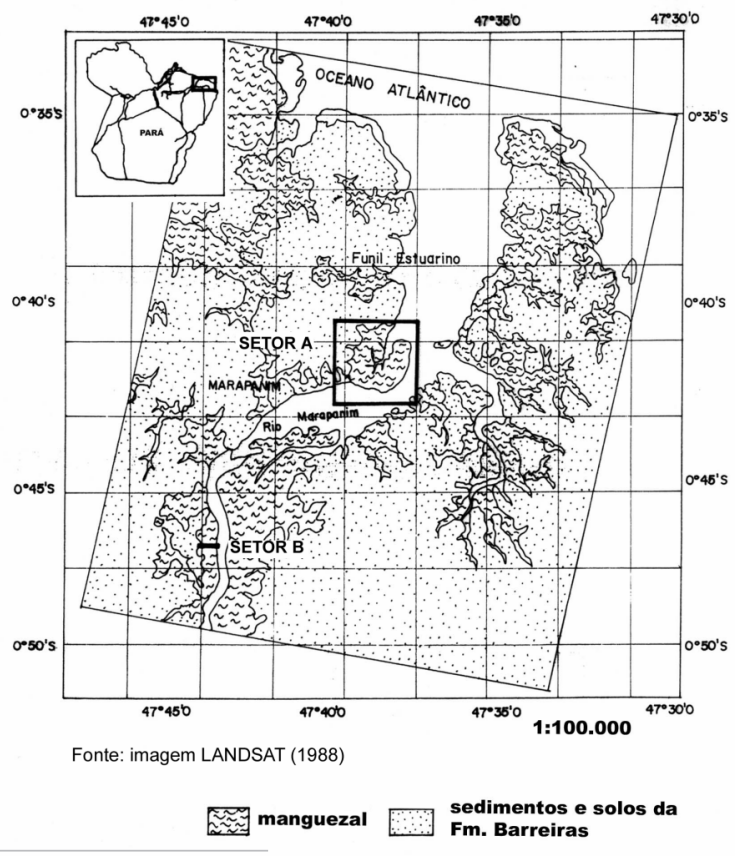

Figura 1 - Mapa de localização

\section{RESULTADOS E DISCUSSÃO}

\section{HIDROQUÍMICA}

As águas do estuário do rio Marapanim são levemente aquecidas (entre $27^{\circ}$ a $30^{\circ} \mathrm{C}$ ), influenciadas pela evaporação nos períodos de estiagem, efeito amenizado quando os alísios de sudeste sopram mais fortemente ou, nas mudanças de maré (Berrêdo, 2006). Os valores de $\mathrm{pH}$ (tabela 1) indicam 
Tabela 1 - Valores médios dos parâmetros analisados no período chuvoso (março/julho) e estiagem (setembro/novembro)

\begin{tabular}{|c|c|c|c|c|c|c|c|c|c|c|c|c|}
\hline \multirow{2}{*}{ Parâmetros } & \multirow{2}{*}{$\mathrm{T}^{0} \mathrm{C}$} & \multirow{2}{*}{$\mathrm{pH}$} & \multirow{2}{*}{ Sal. } & $\mathrm{Cl}^{-}$ & AT & $\mathrm{SO}_{4}{ }^{2-}$ & $\mathrm{H}_{4} \mathrm{SiO}_{4}$ & $\mathrm{PO}^{3-}$ & $\mathrm{Na}^{+}$ & $\mathrm{Mg}^{2+}$ & $\mathrm{Ca}^{2+}$ & $\mathrm{K}^{+}$ \\
\hline & & & & $\mathrm{mmol} / \mathrm{L}$ & $\mathrm{mmol} / \mathrm{L}$ & $\mathrm{mmol} / \mathrm{L}$ & $\mathrm{mmol} / \mathrm{L}$ & $\mu \mathrm{mol} / \mathrm{L}$ & $\mathrm{mmol} / \mathrm{L}$ & $\mathrm{mmol} / \mathrm{L}$ & $\mathrm{mmol} / \mathrm{L}$ & $\mathrm{mmol} / \mathrm{L}$ \\
\hline março & $27 \pm 0,24$ & $5,74 \pm 0,8$ & $2,5 \pm 1,1$ & $34 \pm 14,6$ & $0,49 \pm 0,16$ & $1,53 \pm 1,6$ & $89 \pm 28$ & $0,49 \pm 0,27$ & $44 \pm 31$ & $2,54 \pm 1,4$ & $1 \pm 0,25$ & $0,46 \pm 0,25$ \\
\hline julho & $30 \pm 0,24$ & $6,68 \pm 0,4$ & $10 \pm 3,7$ & $112 \pm 66$ & $1,76 \pm 0,19$ & $6 \pm 2,8$ & $17 \pm 15$ & $0,04 \pm 0,06$ & $26 \pm 17$ & $10 \pm 6$ & $33 \pm 31$ & $0,55 \pm 0,26$ \\
\hline setembro & $29 \pm 0,99$ & $7,88 \pm 0,2$ & $26 \pm 2,1$ & $383 \pm 44$ & $1,76 \pm 0,10$ & $19 \pm 2,7$ & $38 \pm 4,8$ & $0,56 \pm 0,08$ & $71 \pm 5,6$ & $39 \pm 5,8$ & $116 \pm 11$ & $4 \pm 0,46$ \\
\hline novembro & $29 \pm 0,31$ & $7,9 \pm 0,18$ & $29 \pm 1,42$ & $415 \pm 73$ & $1,72 \pm 0,42$ & $21,5 \pm 2,6$ & $81 \pm 49$ & $2,64 \pm 1,36$ & $625 \pm 225$ & $89 \pm 23$ & $85 \pm 47$ & $7,1 \pm 1,35$ \\
\hline
\end{tabular}

condições alcalinas no período de estiagem (variando entre 7,88 a 7,99), principalmente na foz do rio. No período chuvoso, o $\mathrm{pH}$ diminui sensivelmente $(5,74$ a 6,68$)$, acidificadas rio acima pelos ácidos orgânicos produzidos nos manguezais $\left(24-60 \mathrm{~g} \cdot \mathrm{Kg}^{-1}\right)$.

Os valores de salinidade aumentam ao longo do ciclo hidrológico da região costeira, segundo gradiente longitudinal negativo distribuído entre 29 a 1, estabelecido em direção ao interior do estuário. O período de baixa precipitação pluvial caracteriza-se pelo domínio das correntes de marés e as águas salgadas chegam a penetrar mais de $60 \mathrm{~km}$ no estuário. Ao final da estiagem (dezembro), a salinidade atinge sua amplitude máxima, próximo à média da água do mar (35), concentrando-se na foz do rio Marapanim, onde os processos são eminentemente marinhos e os sedimentos salinizados pela intrusão marinha (figura 2), corroborando Wolanski (1986) e Hollins e Ridd (1997).

$\mathrm{Na}$ foz do rio Marapanim ocorrem raras e tênues zonaçóes vegetais compostas de Rhyzophora mangle e Avicennia germinans, associadas com a Spartina brasiliensis nas zonas de sedimentos jovens (acreção lamosa) e a Lagunculária racemosa em terreno siltoso.

Ao longo do estuário, os efeitos de dessalinização dos sedimentos são observados a partir da zona de transição (próximo ao setor B), por meio da substituição gradual da vegetação de mangue por espécies de água doce: Achrosticum aureum e Eutherpe oleraceae, além de velhas e altas árvores (25 a $30 \mathrm{~m}$ ) de Rhyzophora sp. e Avicennia sp.; essa última apresenta acentuado grau de senescência, distribuída em bosques esparsos e mistos, colonizando sedimentos de granulometria síltico-arenosa. Essa é uma implicação biológica importante (Wolanski et al.. 1997; Duke et al. 1998) derivada dos processos hidrosedimentares do rio Marapanim, os quais influenciam a salinidade e condicionam a implantação dos manguezais ao longo do estuário.

Entre os constituintes dissolvidos o $\mathrm{Cl}^{-}$destaca-se como o ânion principal das águas superficiais, segundo a relação: $\mathrm{Cl}>\mathrm{SO}_{4}^{2-}>\mathrm{HCO}_{3}^{-}$e, entre os cátions $\mathrm{Na}^{+}>\mathrm{Ca}^{++}>\mathrm{Mg}^{++}>\mathrm{K}^{+}$. $\mathrm{O}$ aumento sazonal dos teores dos constituintes dissolvidos no período da estiagem é um reflexo do clima sobre a composição química das águas e, também, assinala a intrusão de águas oceânicas no estuário, tendo em vista as baixas concentraçôes de elementos alcalinos e alcalino-terrosos na área-fonte continental, altamente lixiviada pelo intemperismo químico tropical (Kronberg et al.1979).

A sílica possui os maiores teores no período chuvoso (38 a $111 \mu \mathrm{mol} / \mathrm{L}$ ), o que indica em parte a intensa lixiviação da área-fonte. A alcalinidade $(0,21$ a $2,28 \mathrm{mmol} / \mathrm{L})$ e o sulfato (4 a $25 \mathrm{mmol} / \mathrm{L}$ ) são mais elevados na foz do estuário e diminuem continuamente em direção ao interior, devido a maior influência das águas ácidas do rio. As concentrações de ortofosfato são mais elevadas no período de estiagem, com média aproximada 5 vezes maior que as encontradas no período chuvoso $(0,11$ a $1 \mathrm{mmol} / \mathrm{L})$. Na estiagem, esses teores elevam-se em direção à foz e, no período chuvoso, o comportamento é o inverso.
(A)

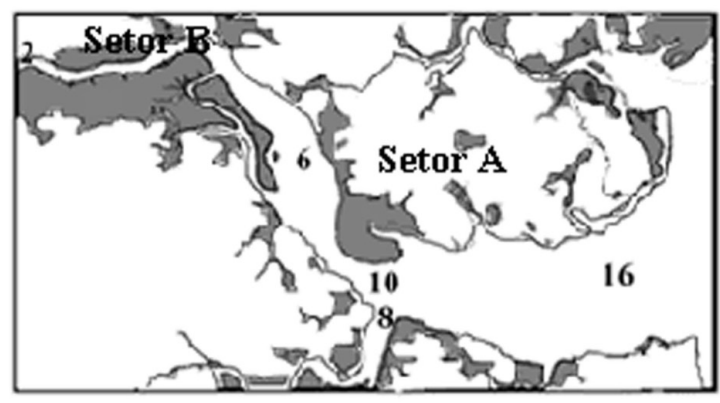

(B)

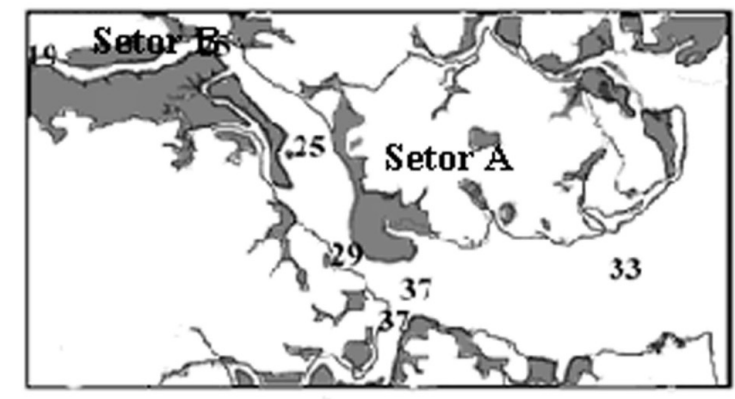

Figura 2 - Distribuição da salinidade em (A), final do período chuvoso e (B), final da estiagem. 


\section{OS SEDIMENTOS DOS MANGUEZAIS}

Os setores A e B são mostrados em detalhe na figura 3. Padrôes diferenciados de drenagem destacam-se nas imagens, associados às características morfológicas do terreno, salientadas nos perfis topográficos I, II e IV. Os sentidos de escoamento superficial indicados com setas nos perfis topográficos, mostram existência de suaves aclives, além de regiōes de depressão e retenção hídrica.

No setor $A$, a interpretação dos padrões de drenagem possibilitou a identificação de duas áreas: a primeira, de textura lisa, que corresponde a uma acresção lamosa recente, por onde passa o perfil I e a segunda, adjacente, com textura rugosa dendrítica, exibindo canais profundos e hierarquizados desenvolvidos sobre terrenos topograficamente mais elevados, onde está o perfil II. O setor B, onde situa-se o perfil IV, representa a região mais elevada topograficamente, com características morfológicas e padróes de drenagem mais desenvolvidos.

No perfil I, mangues jovens, constituídos principalmente Rhizophora mangle, estendem-se pelos primeiros $600 \mathrm{~m}$ e há abundância de tênues canais de maré (não visíveis na imagem). Esse setor representa terrenos topograficamente baixos, onde as marés estão sempre presentes, mesmo em momentos de quadratura. No perfil II, ao contrário, a permanência e o recobrimento pelas marés são dificultados em resposta a zonas de topografia mais elevada (entre 0 e $300 \mathrm{~m}$ e após $900 \mathrm{~m}$ ); os canais de maré são profundos e mais hierarquizados e os sedimentos mais desenvolvidos fisicamente, coexistindo com mangues mais maduros ( 25 a $30 \mathrm{~m}$ ) e estruturalmente bem diferenciados.

Nos terrenos mais elevados do setor A, os sedimentos são oxidados na porção superior, até $40 \mathrm{~cm}$ de profundidade, com Eh de $+200 \mathrm{a}+300 \mathrm{mV}, \mathrm{pH}$ ácido (entre 4 e 5) e a

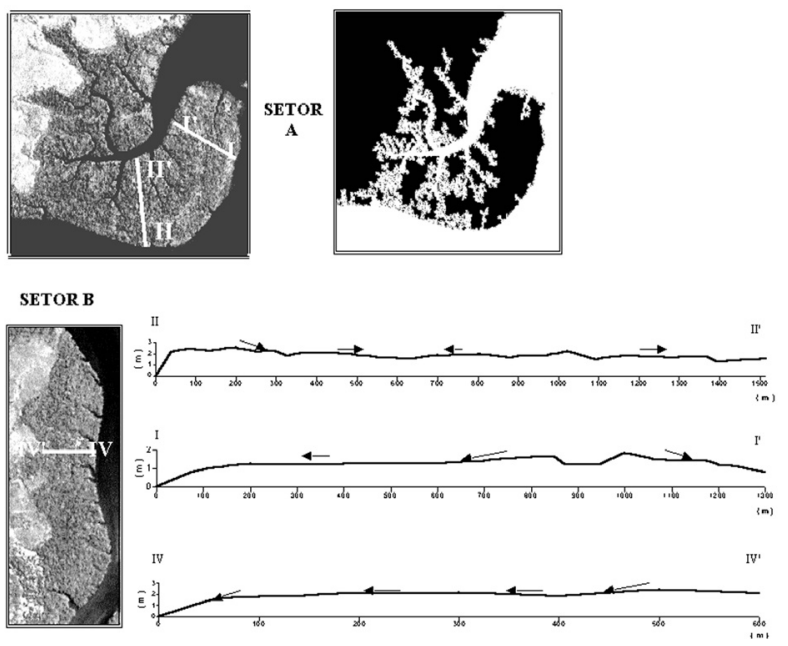

Figura 3 - Detalhes dos setores A e B. Perfis topográficos I, II e IV. salinidade intersticial situa-se entre 40 e 50 e está acima das águas superficiais; esses terrenos são mais susceptíveis às oscilações sazonais (período de chuvas e de estiagem) e às trocas com o meio atmosférico. Os sedimentos apresentam cor marrom-amarelada (10YR 6/3) e mosqueamento provocado por fases oxidadas de ferro recobrindo grãos de quartzo. A matéria orgânica total (\% de C) situa-se em torno de 3\%. Nesse local, a Avicennia germinans, sobressai-se em pontos mais elevados do terreno, embora exista o predomínio total da Rhizophora mangle em locais adjacentes, um pouco mais baixos e úmidos.

Nos terrenos mais jovens (perfil I), a baixa declividade favorece a permanência das águas o ano todo. Em conseqüência, os sedimentos são predominantemente redutores (Eh em torno de $-300 \mathrm{mV}$ ), fracamente ácidos a neutros ( $\mathrm{pH}$ em torno de 6), com salinidade em torno de 40 no período de estiagem. A coloração é cinza-clara a cinza-escura (2.5Y 5/1 a 10YR 4/1), caracterizado pelo aumento do teor de matéria orgânica (4 a $6 \%$ ) e sulfetos dissolvidos. Esses setores são colonizados apenas pela Rhizophora mangle.

No setor B, situado $16 \mathrm{~km}$ rio acima, o perfil IV é menos influenciado pelas marés que nas outras áreas citadas, possui zonas de sedimento lavadas apenas nas marés de equinócio. Nesse setor, os sedimentos de mangue acomodaram-se à margem do rio, recobrindo os sedimentos da Formação Barreiras. Os sedimentos de manguezal mantêmse quase sempre expostos, com salinidade em torno de 30 , desenvolvendo perfil de oxidação forte (Eh entre 0 e +300$)$ entre 40 e $60 \mathrm{~cm}$ de espessura, extremamente ácido $(\mathrm{pH}$ entre 4 e 5) na estiagem, principalmente nos limites com os sedimentos da Formação Barreiras, cuja influência do ferro oxidado empresta cor avermelhada aos sedimentos de mangue. Uma vegetação mista composta de Rhizophora mangle e Avicennia germinans apresenta-se com aspecto mais maduro que a vegetação do setor $A$.

\section{EFEITOS DA SAZONALIDADE SOBRE AS ÁGUAS INTERSTICIAIS E A MINERALOGIA DOS SEDIMENTOS}

Uma maneira eficaz de se investigar as interações climáticas com os sedimentos é por meio das mudanças na química da água intersticial, indicadoras sensíveis de processos diagenéticos em ambientes sedimentares (Lord e Church, 1983; Giblin e Howarth, 1984). Um estudo detalhado foi conduzido no setor A (entre 300 a 400 m no Perfil II), em uma área periodicamente recoberta pelas marés, colonizada exclusivamente por Rhizophora mangle, que se desenvolveu sobre sedimentos síltico-argilosos. Nesse local, a água doce é somente de contribuição pluviométrica; a capacidade de infiltração das águas e, consequentemente, de diluição da água intersticial, é facilitada pelo aumento da permeabilidade na zona de bioturbação, localizada na profundidade máxima de $1 \mathrm{~m}$. ao nível das raízes. Nos sedimentos síltico-argilosos 
dos manguezais da regiáo Bragantina, Schwendenmann et al. (2006), estabeleceram um coeficiente de permeabilidade $(K)$ para a zona de bioturbação situado entre 0,4 e $5 \mathrm{~m} \cdot \mathrm{d}^{-1}$ e, para os mesmos sedimentos, não bioturbados, situados

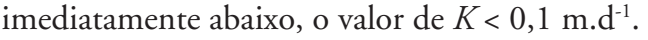

O íon cloreto $(\mathrm{Cl})$ foi utilizado como espécie quimicamente não reativa, cuja concentração é afetada apenas por processos físicos de dessecação dos sedimentos, diluição e difusão (Lord e Church, 1983). Além do íon $\mathrm{Cl}^{-}$, foram utilizados ferro total dissolvido, sulfetos e sulfato, além de $\mathrm{pH}$ e Eh, relacionados à dinâmica do ferro, enxofre e matéria orgânica, para descrever a atuação dos processos de evapotranspiração sobre os sedimentos de mangue (Marchand et al., 2004; Fiot e Gratiot, 2006).

As variações sazonais do $\mathrm{Cl}^{-}$nas águas intersticiais são mostradas na figura 4 . Na superfície $(0 \mathrm{~cm})$ a concentração não ultrapassa $20 \mathrm{~g} / \mathrm{l}$ no período de estiagem (novembro e dezembro) o que reflete a diminuição da chuva e o aumento da evapotranspiração. Nos meses chuvosos (maio e junho), com a diminuição da evapotranspiração, as concentrações situam-se abaixo de $10 \mathrm{~g} / \mathrm{l}$.

As concentrações do $\mathrm{Cl}^{-}$tendem a ficar constantes a partir da profundidade de $40 \mathrm{~cm}$, situando-se entre 10 a 15 $\mathrm{g} / \mathrm{l} \mathrm{em} 65 \mathrm{~cm}$; estes valores situam-se próximos à média das águas de enchente $(15 \mathrm{~g} / \mathrm{l})$ o que evidencia o fluxo do íon pelo sedimentos a partir de $40 \mathrm{~cm}$. A repartição dos valores da salinidade ocorre em torno da profundidade de $1 \mathrm{~m}$, referenciada na área como a zona das raízes mais profundas e onde ocorrem misturas dispersivas com as águas de superfície (Harvey e Odum 1990).

Interessante observar que nos meses chuvosos (maio e junho), a concentração de $\mathrm{Cl}^{-}$na superfície é mais elevada na maré de quadratura (junho), quando os sedimentos são expostos aos fatores atmosféricos e as chuvas, excepcionalmente ausentes durante o período de amostragem. Por outro lado,

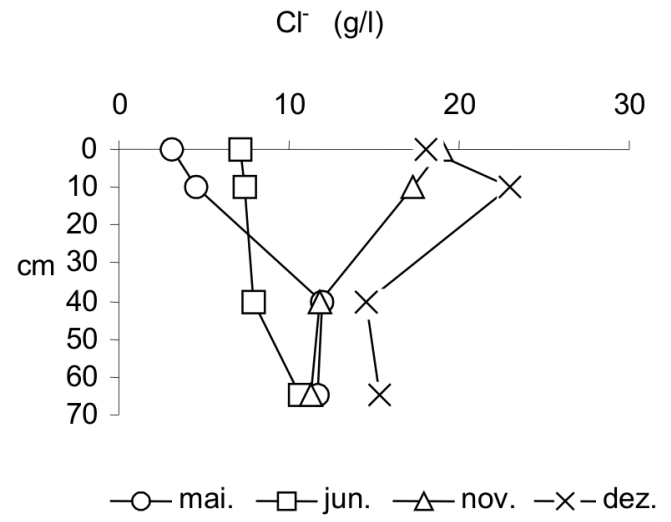

Figura 4 - Variação sazonal do cloreto nas águas intersticiais. nas coletas realizadas nos meses de estiagem (novembro e dezembro), as concentraçôes de $\mathrm{Cl}$ foram maiores nas marés de sizígia (novembro) o que demonstra que a evapotranspiração é fator preponderante para a dessecação desses sedimentos, concordando com os resultados obtidos por Dittmar e Lara (2001) e Schwendenmann et al 2006, para os manguezais da zona Bragantina, Marchand et al. (2004) e Baltzer et al. (2004), na Guiana Francesa.

Os efeitos da variabilidade climática também foram observados sobre os produtos dos processos diagenéticos de oxi-redução da matéria orgânica: sulfetos, sulfatos e ferro dissolvido. No gráfico de geração de sulfetos dissolvidos (figura 5), constata-se a quase inexistência destes íons na profundidade de $0-10 \mathrm{~cm}$, provavelmente oxidados pela exposição dos sedimentos aos fluxos advectivos de oxigênio atmosférico nas marés de quadratura, com reflexos imediatos em teores mais elevados de sulfato (figura 6). Logo abaixo, a produção de sulfetos segue normalmente, com a conseqüente redução nos teores de sulfato dissolvido, segundo a equação:

\section{$\mathrm{H}_{2} \mathrm{~S}(\mathrm{mmol} / \mathrm{l})$}

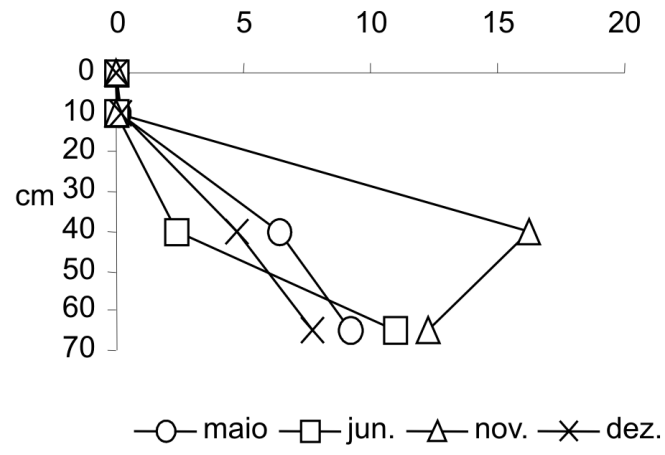

Figura 5 - Distribuição de sulfeto total nas águas intersticiais.

$$
\mathrm{SO}_{4}{ }^{2-(\mathrm{mmol} / \mathrm{l})}
$$

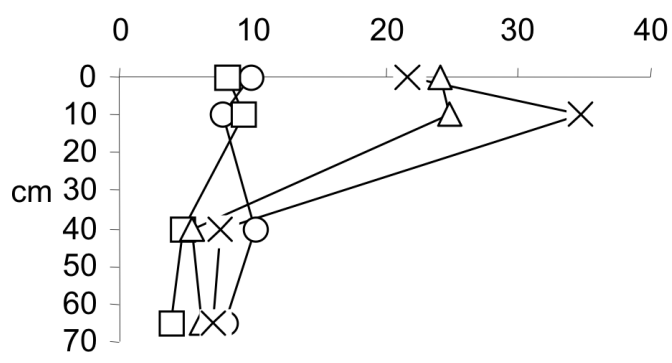

$\multimap-$ maio $\square \square$ jun. $\neg-$ nov. $-\times-$ dez.

Figure 6 - Distribuição de sulfato total nas águas intersticiais. 

(1984).

$\mathrm{H}_{2} \mathrm{~S}_{\text {aq. }}+2 \mathrm{O}_{2} \mathrm{SO}_{4}^{2-}{ }_{\text {aq. }}+2 \mathrm{H}^{+}$(1), de Giblin e Howarth

De acordo com a equação (1), o sulfato é o principal produto formado pela oxidação dos sulfetos dissolvidos na profundidade de $0-10 \mathrm{~cm}$, enquanto que as concentrações de sulfetos dissolvidos são reduzidas próximo à superfície e o $\mathrm{pH}$ torna-se fracamente ácido. A produção de sulfetos dissolvidos é acompanhada por correlações negativas significativas entre sulfato e os sulfetos na profundidade de $30-65 \mathrm{~cm}$, confirmando as fortes relações entre as espécies (Giblin e Howarth, op. cit).

Os teores de ferro total dissolvido aumentam entre 0-10 cm (figura 7). Nessa profundidade, o ferro oxidado é encontrado apenas como película nos grãos de quarto, e é aprisionado logo abaixo onde forma os sulfetos sólidos (pirita, $\mathrm{FeS}_{2}$ ). Indícios da oxidação de sulfetos foram observados na parte superior dos sedimentos no exame de cristais de pirita $\left(\mathrm{FeS}_{2}\right)$, por microscopia eletrônica. As observaçōes microscópicas indicaram a reduzida ocorrência de pirita em cristais diminutos próximo à superfície dos sedimentos (0-10 $\mathrm{cm})$. Sua presença nessa profundidade é perceptível apenas com a detecção por elétrons retro espalhados.

Como reflexo dos processos atuantes, o $\mathrm{pH}$ da superfície $(0 \mathrm{~cm})$ está próximo à neutralidade, com tendência à acidez entre 0 e $10 \mathrm{~cm}$, torna-se alcalino no campo de produção dos sulfetos (figuras 8 e 9). Ao mesmo tempo, o Eh é oxidante (entre 0 e $+200 \mathrm{mV}$ ) em superfície e passa a extremamente redutor em profundidade, tendendo a $-400 \mathrm{mV}$.

A saturação das águas intersticiais nos períodos de estiagem é evidenciada pela formação de minerais evaporíticos (gipso e halita) nos níveis superiores dos sedimentos. Nos períodos úmidos, estes minerais foram identificados em níveis situados abaixo de $40-50 \mathrm{~cm}$, aparentemente como fases reliquiares.

Ferro total dissolvido ( $\mu \mathrm{mol} / \mathrm{l})$

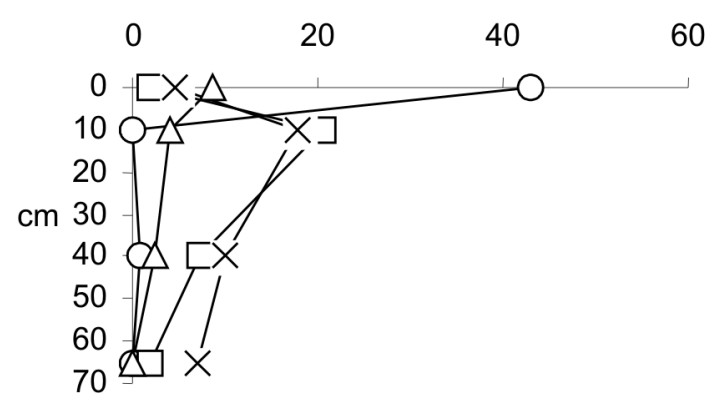

$$
\multimap-\text { maio }-\square-\text { jun. } \triangle-\text { nov. }-x-\text { dez. }
$$

Figura 7 - Distribuição do ferro total dissolvido nas águas intersticiais.
Os resultados apresentados nessa pesquisa são comparáveis ao comportamento sazonal da água intersticial observado nos campos salinos da baia Delaware, nos Estados Unidos (Lord e Church, 1983) e, também, assemelham-se aos de clima equatorial (Camarões, Indonésia e Guiana Francesa) obtidos por Baltzer (1982), Baltzer et al. (1995), Baltzer et al. (2004); Marchand et al. (2004) e Fiot e Gratiot (2006). Segundo esses autores, nos sedimentos lamosos, mesmo sob períodos curtos, porém, com marcante sazonalidade, as propriedades geoquímicas dos sedimentos são alteradas quando as águas intersticiais são submetidas a processos de evaporação significativos. Tais processos originam uma diferenciação vertical e lateral na transição do domínio das águas salgadas-águas doces (salobras), com modificaçōes contínuas e progressivas na salinidade e grau de oxidação.

\section{Eh $(m V)$}

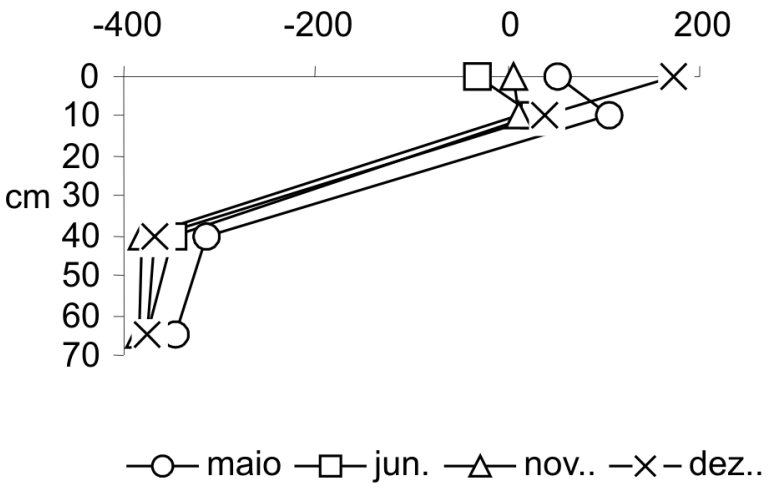

Figura 8 - Distribuição de Eh (mV) nas águas intersticiais.
$\mathrm{pH}$

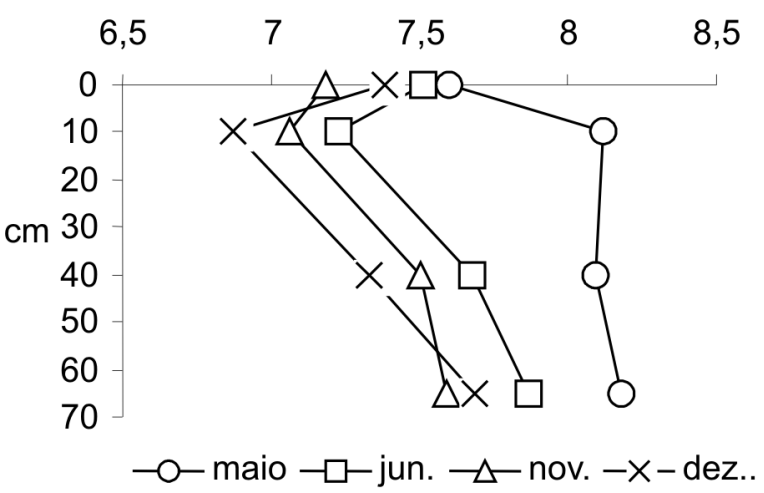

Figura 9 - Distribuição do pH nas águas intersticiais. 


\section{CONCLUSÕES}

O efeito climático na zona costeira do Pará reflete-se, principalmente, na variação do teor de sais das águas estuarinas, verificado entre o período chuvoso e a estiagem. O aumento da evapotranspiração é fator preponderante para a dessecação e a salinização de sedimentos situados topograficamente mais elevados em relação às inundações das marés. A exposição conduz a modificações biogeoquímicas nos sedimentos como a oxidação dos sulfetos dissolvidos, ao aumento da concentração de sulfato e à liberação do ferro em condições fracamente ácidas e oxidantes; o gipso e a halita precipitam das águas interisticiais saturadas em sais. Nossos resultados sugerem que a curta, porém marcante sazonalidade da região, a distribuição anual das chuvas, as características morfológicas e sedimentológicas dos manguezais, a evapotranspiração e o regime das marés, contribuem decisivamente para a oxidação total ou parcial dos sedimentos em superfície, modificando a mineralogia e as características químicas e físico-químicas das águas intersticiais.

\section{AGRADECIMENTOS}

Ao $\mathrm{CNPq}$ pelo apoio financeiro através dos projetos SelenMerAs (Processo 476.874/2001-7) e Geosedintama (Processo 471109/03-7). Ao CNPq pela concessão de bolsa de produtividade de pesquisa e auxílio pesquisa (Grant) ao segundo autor. Ao Museu Emilio Goeldi (MPEG) pela utilização dos laboratórios de análises químicas.

\section{REFERÊNCIAS BIBLIOGRÁFICAS}

Baltzer, F. 1982. La sedimentation et la diagenèse précoce sur les côtes à mangroves. Cah. ORSTOM, Géol. XII, 175-189.

Baltzer, F.; Plaziat, J.C; Prost, M.T.; Rudant, J.P. 1995. Long-term effects of Seasonal changes on geochemical properties of sediments in mangroves-swamps in French Guiana. III Workshop ECOLAB. Belém-Pará. 51-54p.

Baltzer, F.; Allison, M.; Fromard, F. 2004. Material exchange between the continental shelf and mangrove-fringed coasts with special reference to the Amazon-Guianas coast. Marine Geology, (208):115-126.

Berrêdo, J.F; Sales, M.E.; Prost, M.T.; Mendes, A.C.; Senna, C. 1997. Hidroquímica do estuário do Rio Marapanim, Nordeste do Estado do Pará - Brasil. In: WORKSHOP DO PROGRAMA INSTITUCIONAL DE ESTUDOS COSTEIROS. 1., Salinópolis, 1997. Anais. Salinópolis, MCT/CNPq/MPEG p. 26-26.

Berrêdo, J.F. 2006. Geoquímica dos sedimentos de manguezais do nordeste do estado do Pará: o exemplo do estuário do rio Marapanim/Tese de Doutorado, Universidade Federal do Parál Centro de Geociências, Belém, Pará. 185pp.

Carmouze, J.-P. 1994. O metabolismo dos ecossistemas aquáticos (Fundamentos teóricos, métodos de estudo e análises químicas). São Paulo, Edgard Blucher Ltda . 253pp.
Cline, C.D. 1969. Spectrophotometric determination of hydrogen sulfide in natural waters. Limnol. Oceanog., (14): 454-458p.

Duke, N.C.; Ball, M.C.; Ellison, J.C. 1998. Factors influencing biodiversity and distributional gradientes in mangroves. Global Ecology and Biogeography Letters, (7):27-47.

Faure, J.F.F.1999. Manguezais do litoral paraense: Recursos naturais, uso social e indicadores de sustentabilidade - Relatório Parcial Departamento de Ecologia. Museu Paraense Emílio Goeldi. Relatório Interno. 31p.

Fiot, J.; Gratiot, N. 2006. Strutural effects of tidal exposures on mudflats along the French Guiana coast. Marine Geology, (228):25-37.

Garrels, R.M; Christ, C.L. 1965. Solutions, Minerals and Equilibria. Harper et Row Ed. New York, 450 pp.

Giblin, A . E. Howarth, R. W. 1984. Porewater evidence for a dynamic sedimentary iron cycle in salt marshes. Limnology e oceanography, 29 (1): 47-63p.

Grasshoff K. 1983. Methods of sea water analyses, $2^{\text {nd }}$. Edn. Weinheim: Verlag Chemie 317pp.

Harvey, J.W.; Odum, W.E. 1990. The influence of tidal marshes on upland groundwater discharge to estuaries. Biogeochemistry, (10):217-236.

Hollins, S.; Ridd, P. V. 1997. Evaporation over a tropical tidal salt flat. Mangrove and Salt Marshes, (1):95-102.

Kronberg, B.I.; Fyfe, W.S.; Leonardos, O.H. Jr.; Santos, A.M. 1979. The chemistry of some brazilian soils: element mobility during intense weathering. Chemical Geology, (24):211-229.

Lord, C.J. Iii, Church, T.M. 1983. The geochemistry of salt marshes: sedimentary ion Diffusion, sulfate reduction, and pryritization. Geochimica et Cosmochimica Acta, (47): 1381-1391.

Lara, R.; Dittmar, T.. 1999. Nutrient dynamics in a mangrove creek (North Brazil) during dry season. Mangroves Salt Marsh. (3):185-195.

Martorano, L.G. et al. 1993. Estudos climáticos do Estado do Pará, classificação climática (Köppen) e deficiência hídrica (Thornthwhite, Mather). Belém, SUDAM/EMBRAPA, SNLCS, 3p.

Marius, C. 1985. Mangroves du Sénégal et de la Gambia. Trav. et Doc. OSRTOM (193):357.

Marchand, C.; Baltzer, F.; Lallier-Vergès, E.; Albéric, P. 2004. Porewater chemistry in mangrove sediments: relationship with species composition and developmental stages (French Guiana). Marine Geology, (208):361-381.

Pavê, A. 2003 . Assises de la Recherche, plateau des Guyanee. Atelier no 1 - Ecossistèmes Côtiers (não publ.)

Prost, M.T. 1997. Evolução atual e Holocênica do litoral do nordeste do estado do Pará (Relatório Final de Projeto de Pesquisa MPEG/ CNPq, não publ.).

Schwendenmann, L. 1988. Tidal and seasonal variations of soil and water properties in a Brazilian manbrove ecosystem/ M.Sc. Thesis, University of Karlsruhe, Karlsruhe. 101pp.

Schwendenmann, L.; Riecke, R.; Lara, R. J.. 2006. Solute dynamics in a north brasilian mangrove: the influence of sediment 


\section{ACTA}

permeability and freshwater input. Wetland Ecology and Management, (14):463-475.

Sudam .1984. Atlas Climatológico da Amazônia Brasileira. SUDAM/ PHCA. Belém. 125pp.

Thorez, J. 1976. Practical identification of clay minerals. Bélgique, G. Lelotte. 90p.

Wolanski, E. 1986. An evaporation-driven salinity maximum zone in Australian tropical estuaries. Estuarine Coastal and ShelfScience, (22):415-424.

Wolanski, E.; King, W.; Galloway, D. 1997. Salinity intrusion in the fly river estuary, Papua New Guinea. Journal of Coastal Research, 13(4):993-994.

Recebido em 03/03/2007

Aceito em 06/04/2008 
